\title{
Cerebral vasomotor reactivity assessment using Transcranial Doppler and MRI with apnea test
}

\author{
C.R. Campos Herrera ${ }^{1,3}$, G.C. Beltramini ${ }^{2}$, W.M. Avelar ${ }^{1,4}$, F.O. Lima ${ }^{1,5}$ and L.M. Li $i^{1,4}$ \\ ${ }^{1}$ Departamento de Neurologia, Faculdade de Ciências Médicas, Universidade Estadual de Campinas, Campinas, SP, Brasil \\ ${ }^{2}$ Instituto de Física "Gleb Wataghin", Universidade Estadual de Campinas, Campinas, SP, Brasil \\ ${ }^{3}$ Complexo Hospitalar Prefeito Edivaldo Orsi "Ouro Verde", Campinas, SP, Brasil \\ ${ }^{4}$ Brazilian Research Institute for Neuroscience and Neurotechnology (BRAINN), \\ Universidade Estadual de Campinas, Campinas, SP, Brasil \\ ${ }^{5}$ Universidade de Fortaleza, Fortaleza, CE, Brasil
}

\begin{abstract}
Differently from previous studies that used Transcranial Doppler (TCD) and functional MRI (fMRI) for cerebral vasomotor reactivity (CVR) assessment in patients with carotid stenosis (CS), we assessed CVR using an identical stimulus, the BreathHolding Test (BHT). We included 15 patients with CS and 7 age-matched controls to verify whether fMRI responded differently to BHT between groups and to calculate the agreement rate between tests. For TCD, impaired CVR was defined when the mean percentage increase on middle cerebral artery velocities was $\leqslant 31 \%$ on 3 consecutive 30 -s apnea intercalated by 4 -min normal breathing intervals. For fMRI, the percent variation on blood oxygen level-dependent (BOLD) signal intensity in the lentiform nucleus (LN) ipsilateral to the CS (or both LNs for controls) from baseline breathing to apnea was measured. The Euclidian differences between the series of each subject and the series of controls and patients classified it into normal or impaired CVR. We found different percent variations on BOLD-signal intensities between groups $(P=0.032)$. The agreement was good in Controls $(85.7 \% ; \kappa=0.69)$ and overall $(77.3 \% ; \kappa=0.54)$. We conclude that BHT was feasible for CVR assessment on fMRI and elicited different BOLD responses in patients and controls, with a good overall agreement between the tests.
\end{abstract}

Key words: Blood oxygen level dependence; Transcranial Doppler; Carotid stenosis

\section{Introduction}

Patients with critical carotid stenosis (CS) may present reduction of the cerebral perfusion pressure when collateral flow is insufficient. This may lead to a vasodilation of resistance arterioles mainly modulated by $\mathrm{CO}_{2}$ and, secondly, to a decrease in cerebral blood flow (CBF) and an increase in oxygen extraction fraction (OEF) $(1,2)$. The initial vasodilatory response reflects the cerebral vasomotor reactivity (CVR). Impaired CVR is an independent risk factor for ischemic events in patients with CS (3-5).

Positron emission tomography (PET) is the goldstandard method to assess CVR $(1,6)$. However, due to the wide unavailability and high costs of PET, transcranial Doppler ultrasound (TCD) with transient hypercapnia vasodilatory stimuli such as acetazolamide, inhalation of carbon dioxide or breath holding test $(\mathrm{BHT})$ has been used in clinical practice instead (6-12).

More recently, with the advantage of imaging resolution, blood oxygen level-dependent (BOLD) contrast in functional magnetic resonance imaging ( $\mathrm{fMRI}$ ) has been often used for CVR assessment (13-18). fMRI detects changes in the concentration of deoxyhemoglobin, dependent on a complex interplay among $\mathrm{CBF}$, blood volume and cerebral oxygen consumption $(13,19)$. Hypercapnia increases CBF, which reduces the concentration of deoxyhemoglobin leading to an increase in BOLD signal.

Few studies have associated TCD to BOLD-fMRI for CVR assessment, most of them using distinct vasodilatory stimuli $(16,18,20-22)$. Differently, we aimed to assess CVR in patients with CS and controls using an identical vasodilatory stimulus (BHT) in both tests to verify whether BOLD curves responded differently between the groups and, additionally, to calculate the agreement between the tests.

\section{Material and Methods}

\section{Subjects}

Subjects were recruited from the outpatient Neurology Clinic at the Hospital das Clínicas, Universidade Estadual de Campinas (UNICAMP; patients) or among hospital employees, 
Table 1. Demographic data and vascular risk factors in carotid stenosis patients and age-matched controls.

\begin{tabular}{lccc}
\hline & Patients $(\mathrm{n}=15)$ & Controls $(\mathrm{n}=7)$ & $\mathrm{P}$ \\
& $\mathrm{n}(\%)$ & $\mathrm{n}(\%)$ & \\
\hline Male & $11(73)$ & $5(71)$ & $\mathrm{NS}^{*}$ \\
Mean (age/range) & $68 / 52-90$ & $64.5 / 51-85$ & $\mathrm{NS}^{\#}$ \\
Smoking & $11(73)$ & 0 & $0.003^{*}$ \\
Hypertension & $12(80)$ & $2(28)$ & $0.03^{*}$ \\
Dyslipidemia & $14(93)$ & 0 & $<0.0001^{*}$ \\
Diabetes & $3(20)$ & 0 & $\mathrm{NS}^{*}$ \\
Atrial fibrillation & 0 & 0 & $\mathrm{NS}^{*}$ \\
Coronary artery disease & $4(27)$ & 0 & $\mathrm{NS}^{*}$ \\
\hline
\end{tabular}

NS: non-significant; *Fischer exact test; ${ }^{\#}$ Student's $t$-test.

or from a Community Physical Activity program for the elderly (controls) between October 2010 and January 2013.

Sixteen patients (12 males; mean age: 68 years; range: $52-90$ ) with CS $\geqslant 60 \%$ by angiography, $\geqslant 70 \%$ by duplex ultrasound, or $\geqslant 80 \%$ by computed tomography angiography or MRI angiography (CREST criteria) (23), and 7 age-matched controls with no history of cerebrovascular disease ( 5 males; mean age: 64.5 years range: 51-85) were enrolled. One patient (76-year-old male; labeled "P12") was lately excluded from the analysis, as he did not comply with the BHT on fMRI. Therefore, 15 patients were included.

Patients had to be asymptomatic or, if otherwise, have only transient ischemic attack, Amaurosis fugax or syncope. Controls were neurologically healthy and had normal carotid arteries, as seen by duplex ultrasound. Subjects with self-declared respiratory disorders were not included. Subjects with LN lesions or diffuse leukoencephalopathy were excluded, as this could affect the BOLD signal assessment in the region of interest (ROI).

Demographics are shown in Table 1. All subjects provided written informed consent. The study was approved by the institutional review board of the Faculdade de Ciências Médicas of UNICAMP.

\section{Transcranial Doppler ultrasound protocol}

Subjects were evaluated in a quiet room and in supine position. Throughout the session, arterial blood pressure was measured continuously. Expiratory end-tidal $\mathrm{CO}_{2}$ was recorded throughout the experiment through a nasal sampling line attached to a capnometer (Capnocheck ${ }^{\mathrm{TM}}$ II8401 Smiths Medical, USA).

The M1 segment of both middle cerebral arteries (MCA) were identified through the examination of the transtemporal window with a 2-MHz transducer (SONARA ${ }^{\mathrm{TM}}$ Viasys Healthcare, USA) operated by an experienced sonographer (C.R.C.H.). Upon isolating the site of highest flow velocity within the segment, the transducer was held constant through a head frame to measure time-averaged maximum mean velocities (MMV). Lack of a suitable transtemporal window precluded the performance of bilateral examination in 3 controls and in 3 patients with unilateral CS (P01, P08, and P16). In these patients, TCD examination was done ipsilateral to the CS only.

Prior to TCD, all subjects were instructed about BHT, which consisted of an initial 5-min resting time followed by three 30-s periods of transient apnea (verbally coached by the examiner) intercalated by 4-min of normal breathing between them. Subjects were instructed to avoid hyperventilation before breath-holding time as well as to perform a not so deep inspiratory breath-hold in order to prevent a Valsalva episode. After the breath-hold, a quick exhalation of residual air was performed prior to a return to natural breathing, which allowed the measurement of end-tidal $\mathrm{CO}_{2}$ increases as a result of the breath-hold. All participants performed $\mathrm{BHT}$ in the same way and under continuous examiner supervision.

Time-averaged MMV immediately before (baseline) and after each apnea period were recorded. Impaired CVR was considered if the mean percentage increase on the MCA time-averaged MMV from baseline to apnea was $\leqslant 31 \%$ or steal phenomenon occurred (8).

\section{Functional MRI protocol}

fMRI acquisition was performed with a 3.0T MRI scanner (Philips Achieva, Netherlands) and included: 3D T1-weighted image for anatomical reference $(240 \times 240 \times$ $180 \mathrm{~mm}^{3} \mathrm{FOV}, 1.00 \times 1.00 \times 1.00 \mathrm{~mm}^{3}$ voxel size, $240 \times$ $240 \times 180$ matrix, $8^{\circ}$ flip angle, TR=6.9 ms, TE=3.2 ms), FLAIR image for visualization of parenchymal lesions $\left(200 \times 185.71 \times 149 \mathrm{~mm}^{3}\right.$ FOV, $0.45 \times 0.45 \times 4.00 \mathrm{~mm}^{3}$ voxel size, $448 \times 448 \times 30$ matrix, $1 \mathrm{~mm}$ slice gap, $\mathrm{TR}=12,000 \mathrm{~ms}, \mathrm{TE}=140 \mathrm{~ms}, \mathrm{Tl}=2850 \mathrm{~ms}$ ), DWI to assess recent subclinical lesions $\left(230 \times 230 \times 119 \mathrm{~mm}^{3}\right.$ FOV, $0.90 \times 0.90 \times 4.00 \mathrm{~mm}^{3}$ voxel size, $256 \times 256 \times 24$ matrix, $1 \mathrm{~mm}$ slice gap, $90^{\circ}$ flip angle, TR=2198 ms, TE=60 ms, b-value $=1000 \mathrm{~s} / \mathrm{mm}^{2}$ ) and echo-planar image (EPI) to assess the BOLD effect $\left(240 \times 240 \times 120 \mathrm{~mm}^{3}\right.$ FOV, 


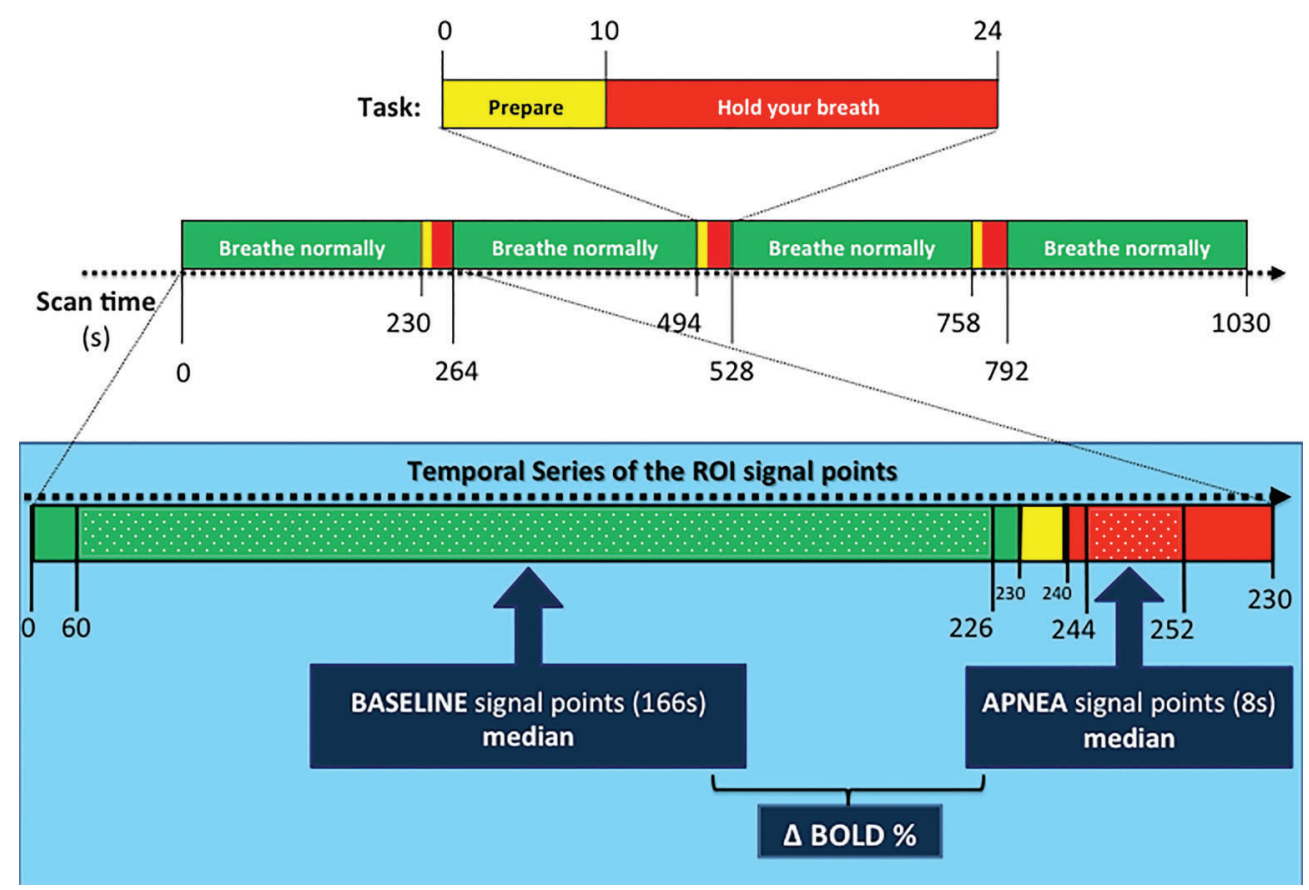

Figure 1. Top: visual BOLD-functional MRI activation paradigm based on traffic lights for instructing subjects on breathing tasks during echo-planar image acquisition. Bottom, within the light blue rectangle: a detailed view of the temporal series of the region of interest (ROI) signal points that were considered for baseline and apnea signal points median calculation, as well as the for the percent variation in the magnitude of stimulus-induced BOLD signal (delta BOLD\%).

$3.00 \times 3.00 \times 3.00 \mathrm{~mm}^{3}$ voxel size, $80 \times 80 \times 40$ matrix, no slice gap, $90^{\circ}$ flip angle, TR=2000 ms, TE=30 ms).

Prior to scanning, all subjects were instructed to stay as still as possible while on $\mathrm{FMRI}$ examination and to look continually at a computer screen (Eloquence, Invivo, USA) positioned on the head coil for breath-hold paradigm instructions. Breathing tasks were displayed in traffic lights-based visual commands: green screen for normal breathing ( $3 \min 50 \mathrm{~s}$ ); yellow, for normal breathing in preparation for holding (10 s); and red, for an inspiratory breath holding (24 s). This sequence was repeated 3 times in the same EPI acquisition (total: $17 \min 12 \mathrm{~s}$ ), ending with a 4-min green screen. The instructions were the same as done earlier, i.e., to avoid hyperventilation before breath-holding time as well as to perform a not so deep inspiratory breath-hold in order to prevent Valsalva. A respiratory gating belt was used for apnea monitoring.

Functional images were visually examined to detect gross artifacts and preprocessed with SPM8 (http://www. fil.ion.ucl.ac.uk/spm) running on MATLAB R2010a (The MathWorks, Inc., USA). The images were realigned (6-parameter rigid body transformation), normalized to standard Montreal Neurological Institute space using the unified segmentation (24) and spatially smoothed with a Gaussian kernel of $6 \mathrm{~mm}$ full width at half maximum.
For the patients, the ROI was the LN ipsilateral to the stenosis. In patients with bilateral CS, the ROI was ipsilateral to the higher-grade stenosis. In controls, both LN were used. LN masks were provided by the WFU PickAtlas toolbox (about 400 voxels each). The extracted signal is the average value of all the voxels inside the ROI. The average signal of both $\mathrm{LN}$ was extracted and corrected for motion through a multiple linear regression with 6 motion parameters from preprocessing (25).

To avoid any hemodynamic and respiratory signal changes related either to breath holding or to inspiration or expiration movements, we considered for baseline BOLD signal the instants when the subject was looking at the green screen and excluded $4 \mathrm{~s}$ of the signal that preceded the yellow screen presentation and $60 \mathrm{~s}$ after the red screen. From this set of baseline signal points, we calculated the median rather than the average in order to avoid the effect of outliers. The stimulus-induced BOLD signal level was calculated through the analysis of the interval from 4 to $12 \mathrm{~s}$ after the onset of breath holding, as the series showed greater differences between them at this period. Afterwards, the percent variation in the magnitude of stimulus-induced BOLD signal (delta-BOLD\%) was calculated in relation to the baseline median BOLD signal level (Figure 1). 
The temporal series of the ROI of controls and patients were individually analyzed by a researcher who was blind to TCD results. Each subject was then classified as normal or abnormal CVR. Since the number of subjects was small, the training data for the classifier was the whole data with the time series of the current subject removed. The average signal across all remaining individuals in each group (controls and patients) was calculated. Then, the Euclidian distance between the series of the current subject and the series of each group was compared. The smallest distance guided the classification: if the distance between the series of a given subject and the series of the controls was smaller than the distance between this subject and the series of patients, then CVR was considered normal.

\section{Statistical analysis}

Patients and controls were classified by each one of the tests into normal or impaired CVR. Afterwards, the agreement was calculated through Cohen's kappa coefficient ( $\kappa)$. Comparisons of nominal data and age distribution between groups were performed with Fisher's exact test and two-tailed Student's $t$-test, respectively. The comparison of the delta-BOLD\% between groups was done with the Mann-Whitney test. In all tests, $\mathrm{P}<0.05$ was considered to be statistically significant.

\section{Results}

On TCD, impaired CVR was detected in 2 of the 7 controls (men; 70 and 85 years old). The oldest one had well-controlled hypertension; the youngest one had no risk factors. Among patients, 10 of 15 showed impaired CVR. Demographic, TCD and fMRI data are shown in Table 2.

For $\mathrm{fMRI}$, the graphical shape of the temporal variation of delta-BOLD\% response during the 3 phases of the paradigm (yellow, red and green) typically consisted of an expressive increase in the signal intensity during the yellow screen followed by a deep undershoot on the apnea time (in the first $10 \mathrm{~s}$ of the red screen), and then a second increase while going from the red screen into the first few seconds of the green screen followed by a decrease towards the baseline signal intensity while resuming normal breathing.

However, the delta BOLD\% signal was significantly different between the groups, particularly in the interval between 4 and $12 \mathrm{~s}$ after the onset of breath hold (MannWhitney test, $P=0.032$ ). The individual analysis of the temporal series of the ROI of all the subjects classified 3 controls and 10 patients as having impaired CVR. Both groups performed similarly for the BHT task, except patient "P12", excluded for not accomplishing BHT on fMRI (Figure 2).

There was an $85.7 \%(6 / 7)$ observed rate of agreement between TCD and fMRI with a good Cohen's kappa coefficient $(\kappa=0.69)$ for controls. For patients, the agreement between TCD and fMRI was fair (73.3\%; 11/15; $\kappa=0.43)$. Overall, TCD and $\mathrm{fMRI}$ showed a good agreement $(77.27 \% ; 17 / 22 ; \kappa=0.54)$.

\section{Discussion}

The goal of the present study was to assess CVR in patients with CS and age-matched controls through TCD and $\mathrm{fMRI}$ using an identical vasodilatory stimulus on both. The delta-BOLD\% curve was significantly different between patients and controls. Additionally, there was good agreement between the tests for controls and overall. Within the patient group, the agreement was fair only. Our study is original because: 1) BHT was used for inducting transient hypercapnia in both TCD and $\mathrm{FMRI}$; 2) controls were included; 3 ) LN was the ROI, and 4) the agreement between TCD and fMRI results was primarily assessed.

We chose BHT because of its low cost, easy performance and overall good correlation to other vasodilatory stimuli $(8,26)$. BHT can cause some concomitant hypoxia during hypercapnia, which may influence the ventilatory response (27) and, additionally, have some issues related to the within-observer long-term reproducibility (28). However, we argue that the short duration of each apnea in our study as well as the fact that TCD measurements were obtained by only one examiner and on a short-term basis have probably reduced those disadvantages.

We included controls to verify whether fMRI with BHT would be able to detect any impairment on CVR, compared to TCD, even in the absence of CS. In our study, the signal averaged time series of BOLD response to BHT in the ROI elicited roughly similar graphical shapes in both groups.

Regarding the graphical shape of the temporal variation of delta-BOLD\% during the 3 phases of the paradigm (yellow, red and green), we argue that the increase on the delta-BOLD\% in the very last seconds of the yellow phase may have occurred because, in spite of being instructed to avoid hyperventilation, it is possible that subjects may have performed inspiratory movements in a deeper way than the expiratory ones, leading to some degree of $\mathrm{CO}_{2}$ retention just before apnea. The curve then decreases within the first 10 seconds of the red screen probably because, at that point, in spite of the progressive increase on the $\mathrm{CO}_{2}$ concentration, the concentration of oxygenated hemoglobin is still higher than the concentration of deoxygenated hemoglobin. As the apnea period continues, $\mathrm{CO}_{2}$ concentration increases and the concentration of deoxyhemoglobin overcomes the concentration of oxyhemoglobin. So the delta-BOLD\% curve goes up again towards the first few seconds of the green screen period, when the concentration of deoxyhemoglobin is still higher as there is a physiological delay for the wash out process. As the normal breathing is resumed, the deltaBOLD\% curve goes down and back into a steady stage. 
Table 2. Demographic data and vascular parameters in carotid stenosis patients and age-matched controls.

\begin{tabular}{|c|c|c|c|c|c|c|c|}
\hline \multirow{2}{*}{$\begin{array}{l}\text { Subject/ } \\
\text { Gender/ } \\
\text { Age }\end{array}$} & \multirow{2}{*}{$\begin{array}{l}\text { Vascular risk } \\
\text { factors }\end{array}$} & \multirow{2}{*}{$\begin{array}{c}\text { Percent } \\
\text { stenosis grade } \\
\text { (right/left) }\end{array}$} & \multirow[t]{2}{*}{ Symptoms } & \multirow{2}{*}{$\begin{array}{c}\text { Mean \% increase } \\
\text { on MCA velocities } \\
\text { (right/left) }\end{array}$} & \multicolumn{2}{|c|}{ CVR } & \multirow{2}{*}{$\begin{array}{c}\text { Agreement } \\
\text { between TCD } \\
\text { and } \mathrm{FMRI}\end{array}$} \\
\hline & & & & & on TCD & on fMRI & \\
\hline \multicolumn{8}{|l|}{ Controls } \\
\hline $\mathrm{C} 01 / \mathrm{M} / 52$ & & & & 62.1/n.a. & $\mathrm{N}$ & I & \\
\hline $\mathrm{C} 02 / \mathrm{F} / 53$ & & & & 56.2/n.a. & $\mathrm{N}$ & $\mathrm{N}$ & Yes \\
\hline $\mathrm{C} 03 / \mathrm{F} / 51$ & & & & 54.8/n.a. & $\mathrm{N}$ & $\mathrm{N}$ & Yes \\
\hline $\mathrm{C} 04 / \mathrm{M} / 76$ & $\mathrm{H}$ & & & $52.42 / 35.8$ & $\mathrm{~N}$ & $\mathrm{~N}$ & Yes \\
\hline $\mathrm{C} 05 / \mathrm{M} / 65$ & & & & $61.1 / 51.6$ & $\mathrm{~N}$ & $\mathrm{~N}$ & Yes \\
\hline $\mathrm{C} 06 / \mathrm{M} / 85$ & $\mathrm{H}$ & & & $21.3 / 25.3$ & 1 & I & Yes \\
\hline $\mathrm{C} 07 / \mathrm{M} / 70$ & & & & $16.9 / 17.04$ & I & I & Yes \\
\hline \multicolumn{8}{|l|}{ Patients } \\
\hline $\mathrm{P} 01 / \mathrm{F} / 63$ & S; Dy & $70 /(-)$ & None & 42.5/n.a. & $\mathrm{N}$ & $\mathrm{N}$ & Yes \\
\hline $\mathrm{P} 02 / \mathrm{M} / 72$ & $\mathrm{~S} ; \mathrm{H} ; \mathrm{Dy} ; \mathrm{CAD}$ & $(-) / 80$ & TIA & $42.88 / 17.36$ & 1 & 1 & Yes \\
\hline $\mathrm{P} 03 / \mathrm{M} / 73$ & $\mathrm{~S} ; \mathrm{H} ; \mathrm{Dy} ; \mathrm{CAD}$ & $90 /(-)$ & Carotid murmur & $20.96 / 28.35$ & I & I & Yes \\
\hline $\mathrm{P} 04 / \mathrm{M} / 52$ & S; Dy & $80 / 90$ & Syncope & $29.18 / 13.01$ & I & I & Yes \\
\hline $\mathrm{P} 05 / \mathrm{M} / 66$ & $\mathrm{H}$ & $>70 /(-)$ & Syncope & $19.06 / 27.12$ & 1 & $\mathrm{~N}$ & \\
\hline $\mathrm{P} 06 / \mathrm{M} / 74$ & $\mathrm{~S} ; \mathrm{H} ; \mathrm{Dy} ; \mathrm{CAD}$ & $(-) />70$ & None & $21.06 / 30.15$ & I & I & Yes \\
\hline $\mathrm{P} 07 / \mathrm{M} / 59$ & S; Dy & $>70 />90$ & AFug;TIA; LS & $21.40 / 11.1$ & I & I & Yes \\
\hline P08/F/69 & $\mathrm{S} ; \mathrm{H} ; \mathrm{Dy}$ & $(-) / 70$ & Dizziness & n.a./74.6 & $\mathrm{N}$ & $\mathrm{N}$ & Yes \\
\hline P09/M/69 & S; H; Dy & $(-) / 80$ & TIA & $34.7 / 36.2$ & $\mathrm{~N}$ & $\mathrm{~N}$ & Yes \\
\hline $\mathrm{P} 10 / \mathrm{M} / 61$ & S; H; Dy & $(-) />90$ & Cerebellar stroke & $40.8 / 37.84$ & $\mathrm{~N}$ & I & \\
\hline $\mathrm{P} 11 / \mathrm{F} / 67$ & $\mathrm{H} ; \mathrm{D} ; \mathrm{Dy}$ & $70 /(-)$ & None & $36.84 / 54.3$ & $\mathrm{~N}$ & I & \\
\hline $\mathrm{P} 13 / \mathrm{M} / 65$ & $\mathrm{~S} ; \mathrm{H} ; \mathrm{Dy} ; \mathrm{CAD}$ & $>70 />70$ & None & $23.25 / 36.8$ & 1 & 1 & Yes \\
\hline $\mathrm{P} 14 / \mathrm{M} / 60$ & $\mathrm{~S} ; \mathrm{H} ; \mathrm{D} ; \mathrm{Dy}$ & $80 /(-)$ & None & $25.65 / 22.76$ & I & $\mathrm{N}$ & \\
\hline $\mathrm{P} 15 / \mathrm{M} / 90$ & $\mathrm{H}$; Dy & $70 /(-)$ & TIA & $-2.6 /-13.8$ & 1 & 1 & Yes \\
\hline $\mathrm{P} 16 / \mathrm{F} / 76$ & $\mathrm{H} ; \mathrm{D} ; \mathrm{Dy}$ & $(-) / 80$ & None & n.a./26.67 & 1 & I & Yes \\
\hline
\end{tabular}

F: female; M: male; H: hypertension; S: former or current smoker; Dy: dyslipidemia; D: diabetes; CAD: coronary artery disease; TIA: transient ischemic attack; AFug: Amaurosis fugax; LS: lacunar stroke; MCA: middle cerebral artery; CVR: cerebrovascular reactivity; TCD: transcranial Doppler; fMRI: functional MRI; N: Normal; I: Impaired; (-): no stenosis; n.a.: suitable transtemporal window not available.

Delta-BOLD\% signal was significantly lower in patients than in controls. This may reflect the degree of collateralization, slow flow, as well as an increased baseline oxygen extraction fraction in patients as compared to controls. Additionally, patients showed a slight delay on the time-to-peak, which may suggest some degree of hypoperfusion or even an uncoupling of blood flow and metabolism (29,30). Chang et al. (29) applied BHT in 17 patients with unilateral CS, in which impairment of CVR was evaluated directly by the comparison of the dynamic pattern of BOLD change over the MCA territory between the hemispheres, considering the contralateral hemisphere as an inner control for each patient. In that study, most patients showed a great heterogeneity regarding BOLD curves, which might have resulted either from the wideness of the chosen ROI or from the lack of an outer control. We argue that the role of the contralateral hemisphere as an inner control is not appropriate, as the presence of a microvascular dysfunction in the nonstenotic hemisphere may conceal any eventual difference on the expected BOLD responses leading to a false negative interpretation. This probably could be overcome with age-matched controls inclusion. However, as CVR impairment may result either from macrovascular effects of CS on perfusion as well as from microvascular dysfunctions (31), which may explain the CVR impairment observed in some of our controls $(28 \%$ by TCD; $43 \%$ by $\mathrm{fMRI}$ ) as this group was matched for age only, but not for vascular risk factors.

LN was chosen as the ROI because of its dense arteriolar irrigation and earlier BOLD response to transient hypercapnia stimuli than other locations $(29,32,33)$. Besides, as a more centered structure, it is less susceptible to peripheral movement artifacts. Another particular interesting point for choosing $\mathrm{LN}$ while using $\mathrm{BHT}$ as the vasodilatory stimulus is that its neurons are directly involved in the complex network of cortical and subcortical structures integrated by the pons that, in turn, exerts inhibitory effect on medullary respiratory neurons during voluntary apnea (34). 


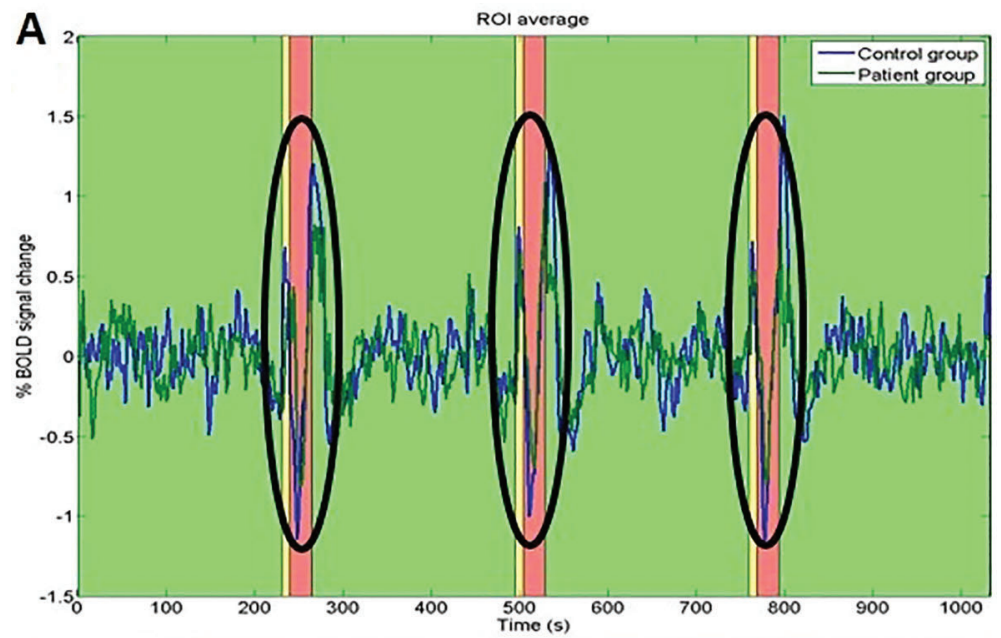

Figure 2. $A$, mean $B O L D \%$ signal variation in the time series during paradigm patients and controls. $B$, averaged delta BOLD\% signal, which was significantly different between groups $(P=0.032$, Mann-Whitney test). $C$, visually different BOLD signal curves were observed in both left and right lentiform nucleus of the patient $\mathrm{P} 12$, who did not comply with the breath-holding test. In $A, B$ and $C$, the background colors represent the paradigm tasks during the green (normal breathing), yellow (normal breathing in preparation for holding) and red screen (breath holding).
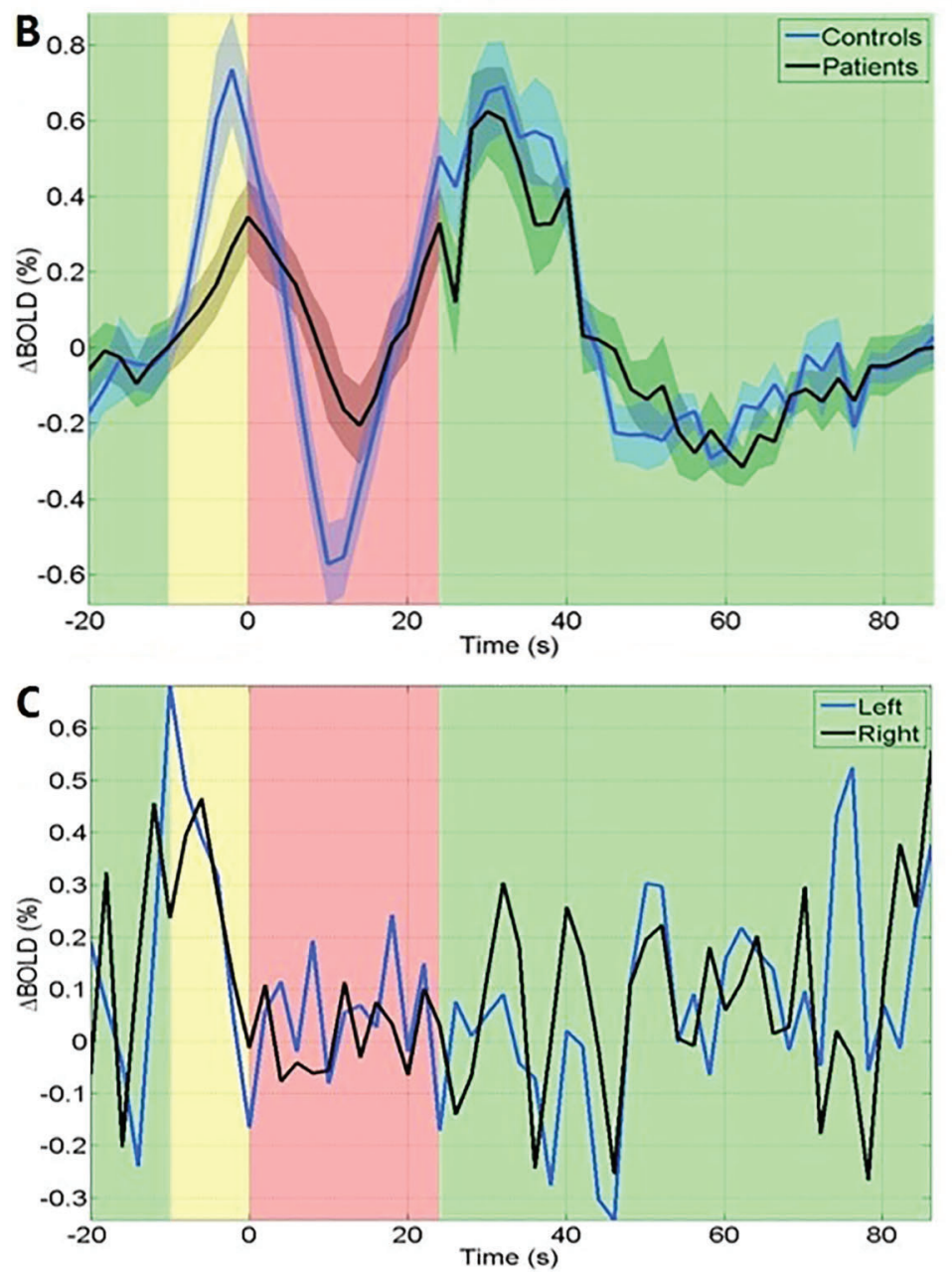

Most of the studies that used TCD and FMRI for CVR assessment in patients with CS or occlusion were primarily aimed to investigate singularities of BOLD curves in response to several paradigms rather than the agreement between the methods $(15,16,18,20-22)$. Even so, two studies with carbon dioxide inhalation demonstrated a 
good agreement between TCD and fMRI $(20,22)$. In our study, the agreement was overall good, but only fair in patients. This may be due to the small sample or, probably, to the fact that TCD was arbitrarily set as the reference test as PET was not available in our institution. The reliability of TCD for CVR screening in patients with CS is still controversial: few studies have shown a good correlation between CBF velocity in the MCA measured by TCD and the blood flow volume assessed by PET $(6,11,12)$, but the association between increased OEF on PET and impaired CVR on TCD has not been consistently found (35).

In conclusion, our study supports that $\mathrm{PMRI}$ with $\mathrm{BHT}$ is a feasible and useful tool for mapping CVR in patients with carotid stenosis, as MRI can overcome some of the main

\section{References}

1. Derdeyn CP, Grubb RL Jr, Powers WJ. Cerebral hemodynamic impairment: methods of measurement and association with stroke risk. Neurology 1999; 53: 251-259, doi: 10.1212/WNL.53.2.251.

2. Derdeyn CP, Videen TO, Yundt KD, Fritsch SM, Carpenter DA, Grubb RL, et al. Variability of cerebral blood volume and oxygen extraction: stages of cerebral haemodynamic impairment revisited. Brain 2002; 125: 595-607, doi: 10.1093/ brain/awf047.

3. Markus H, Cullinane M. Severely impaired cerebrovascular reactivity predicts stroke and TIA risk in patients with carotid artery stenosis and occlusion. Brain 2001; 124: 457-467, doi: 10.1093/brain/124.3.457.

4. Webster MW, Makaroun MS, Steed DL, Smith HA, Johnson $\mathrm{DW}$, Yonas $\mathrm{H}$. Compromised cerebral blood flow reactivity is a predictor of stroke in patients with symptomatic carotid artery occlusive disease. J Vasc Surg 1995; 21: 338-344, doi: 10.1016/S0741-5214(95)70274-1.

5. Yonas H, Smith HA, Durham SR, Pentheny SL, Johnson DW. Increased stroke risk predicted by compromised cerebral blood flow reactivity. J Neurosurg 1993; 79: 483489, doi: 10.3171/jns.1993.79.4.0483.

6. Rijbroek A, Boellaard R, Vriens EM, Lammertsma AA, Rauwerda JA. Comparison of transcranial Doppler ultrasonography and positron emission tomography using a three-dimensional template of the middle cerebral artery. Neurol Res 2009; 31: 52-59, doi: 10.1179/174313208 X325191.

7. Ringelstein EB, Sievers C, Ecker S, Schneider PA, Otis SM. Noninvasive assessment of $\mathrm{CO}_{2}$-induced cerebral vasomotor response in normal individuals and patients with internal carotid artery occlusions. Stroke 1988; 19: 963-969, doi: 10.1161/01.STR.19.8.963.

8. Markus HS, Harrison MJ. Estimation of cerebrovascular reactivity using transcranial Doppler, including the use of breath-holding as the vasodilatory stimulus. Stroke 1992; 23: 668-673, doi: 10.1161/01.STR.23.5.668.

9. Silvestrini M, Troisi E, Matteis M, Cupini LM, Caltagirone C. Transcranial Doppler assessment of cerebrovascular reactivity in symptomatic and asymptomatic severe carotid limitations of TCD: the operator-dependence, the need for an ultrasonic window and the lack of imaging. Further studies with larger samples of patients and age- and vascular risk-matched controls may provide a more accurate measure of the agreement between these methods.

\section{Acknowledgments}

The institutional support of Prof. Fernando Cendes and the Neurovascular Study Group, as well as the kind assistance of Ms. Isilda Assumpcao (RN) and team, are gratefully acknowledged. This research was supported by FAPESP (Process 2010/52027-1 and 2013/07559-3) and CNPq (Process 480976/2010-4).

stenosis. Stroke 1996; 27: 1970-1973, doi: 10.1161/01. STR.27.11.1970.

10. Silvestrini $M$, Vernieri F, Pasqualetti $P$, Matteis $M$, Passarelli $F$, Troisi $E$, et al. Impaired cerebral vasoreactivity and risk of stroke in patients with asymptomatic carotid artery stenosis. JAMA 2000; 283: 2122-2127, doi: 10.1001/jama.283.16.2122.

11. Poeppel TD, Terborg C, Hautzel H, Herzog H, Witte OW, Mueller HW, et al. Cerebral haemodynamics during hypo- and hypercapnia: determination with simultaneous 150-butanolPET and transcranial Doppler sonography. Nuklearmedizin 2007; 46: 93-100.

12. Persoon S, Kappelle LJ, van Berckel BN, Boellaard R, Ferrier $\mathrm{CH}$, Lammertsma AA, et al. Comparison of oxygen15 PET and transcranial Doppler $\mathrm{CO}_{2}$-reactivity measurements in identifying haemodynamic compromise in patients with symptomatic occlusion of the internal carotid artery. EJNMMI Res 2012; 2: 30, doi: 10.1186/2191-219X-2-30.

13. Ogawa S, Lee TM, Kay AR, Tank DW. Brain magnetic resonance imaging with contrast dependent on blood oxygenation. Proc Natl Acad Sci U S A 1990; 87: 98689872, doi: 10.1073/pnas.87.24.9868.

14. Hedera P, Lai S, Lewin JS, Haacke EM, Wu D, Lerner AJ, et al. Assessment of cerebral blood flow reserve using functional magnetic resonance imaging. J Magn Reson Imaging 1996; 6: 718-725, doi: 10.1002/jmri.1880060504.

15. Carusone LM, Srinivasan J, Gitelman DR, Mesulam MM, Parrish TB. Hemodynamic response changes in cerebrovascular disease: implications for functional MR imaging. AJNR Am J Neuroradiol 2002; 23: 1222-1228.

16. Herzig R, Hlustik P, Skoloudik D, Sanak D, Vlachova I, Herman $M$, et al. Assessment of the cerebral vasomotor reactivity in internal carotid artery occlusion using a transcranial Doppler sonography and functional MRI. J Neuroimaging 2008; 18: 38-45, doi: 10.1111/j.1552-6569.2007.00168.x.

17. Mandell DM, Han JS, Poublanc J, Crawley AP, Stainsby JA, Fisher JA, et al. Mapping cerebrovascular reactivity using blood oxygen level-dependent MRI in Patients with arterial steno-occlusive disease: comparison with arterial spin labeling MRI. Stroke 2008; 39: 2021-2028, doi: 10.1161/ STROKEAHA.107.506709. 
18. Altamura C, Reinhard M, Vry MS, Kaller CP, Hamzei F, Vernieri $F$, et al. The longitudinal changes of BOLD response and cerebral hemodynamics from acute to subacute stroke. A fMRI and TCD study. BMC Neurosci 2009; 10: 151-162, doi: 10.1186/1471-2202-10-151.

19. Heeger DJ, Ress D. What does fMRI tell us about neuronal activity? Nat Rev Neurosci 2002; 3: 142-151, doi: 10.1038/ nrn730.

20. Lythgoe DJ, Williams SC, Cullinane M, Markus HS. Mapping of cerebrovascular reactivity using BOLD magnetic resonance imaging. Magn Reson Imaging 1999; 17: 495-502, doi: 10.1016/S0730-725X(98)00211-2.

21. Rossini PM, Altamura C, Ferretti A, Vernieri F, Zappasodi F, Caulo M, et al. Does cerebrovascular disease affect the coupling between neuronal activity and local haemodynamics? Brain 2004; 127: 99-110, doi: 10.1093/brain/awh012.

22. Ziyeh S, Rick J, Reinhard M, Hetzel A, Mader I, Speck O. Blood oxygen level-dependent MRI of cerebral $\mathrm{CO}_{2}$ reactivity in severe carotid stenosis and occlusion. Stroke 2005; 36 : 751-756, doi: 10.1161/01.STR.0000157593.03470.3d.

23. Mantese VA, Timaran CH, Chiu D, Begg RJ, Brott TG. The Carotid Revascularization Endarterectomy versus Stenting Trial (CREST): stenting versus carotid endarterectomy for carotid disease. Stroke 2010; 41: S31-S34, doi: 10.1161/ STROKEAHA.110.595330.

24. Ashburner J, Friston KJ. Unified segmentation. Neuroimage 2005; 26: 839-851, doi: 10.1016/j.neuroimage.2005.02.018.

25. Maldjian JA, Laurienti PJ, Kraft RA, Burdette JH. An automated method for neuroanatomic and cytoarchitectonic atlasbased interrogation of fMRI data sets. Neuroimage 2003; 19 : 1233-1239, doi: 10.1016/S1053-8119(03)00169-1.

26. Muller M, Voges M, Piepgras U, Schimrigk K. Assessment of cerebral vasomotor reactivity by transcranial Doppler ultrasound and breath-holding. A comparison with acetazolamide as vasodilatory stimulus. Stroke 1995; 26: 96-100, doi: 10.1161/01.STR.26.1.96.

27. Ainslie PN, Duffin J. Integration of cerebrovascular $\mathrm{CO} 2$ reactivity and chemoreflex control of breathing: mechanisms of regulation, measurement, and interpretation. Am J Physiol Regul Integr Comp Physiol 2009; 296: R1473-R1495, doi: 10.1152/ajpregu.91008.2008.

28. Totaro R, Marini C, Baldassarre M, Carolei A. Cerebrovascular reactivity evaluated by transcranial Doppler: reproducibility of different methods. Cerebrovasc Dis 1999; 9: 142-145, doi: 10.1159/000015943.

29. Chang TY, Kuan WC, Huang $\mathrm{KL}$, Chang $\mathrm{CH}$, Chang YJ, Wong HF, et al. Heterogeneous cerebral vasoreactivity dynamics in patients with carotid stenosis. PLoS One 2013; 8: e76072, doi: 10.1371/journal.pone.0076072.

30. Roc AC, Wang J, Ances BM, Liebeskind DS, Kasner SE, Detre JA. Altered hemodynamics and regional cerebral blood flow in patients with hemodynamically significant stenoses. Stroke 2006; 37: 382-387, doi: 10.1161/01.STR. 0000198807.31299 .43 .

31. Ficzere A, Valikovics A, Fulesdi B, Juhasz A, Czuriga I, Csiba L. Cerebrovascular reactivity in hypertensive patients: a transcranial Doppler study. J Clin Ultrasound 1997; 25: 383-389, doi: 10.1002/(SICl)1097-0096(199709)25:7<383:: AID-JCU6 > 3.0.CO;2-6.

32. Bright MG, Bulte DP, Jezzard P, Duyn JH. Characterization of regional heterogeneity in cerebrovascular reactivity dynamics using novel hypocapnia task and BOLD fMRI. Neuroimage 2009; 48: 166-175, doi: 10.1016/j.neuroimage.2009.05.026.

33. Hamzei F, Knab R, Weiller C, Rother J. The influence of extra- and intracranial artery disease on the BOLD signal in FMRI. Neuroimage 2003; 20: 1393-1399, doi: 10.1016/ S1053-8119(03)00384-7.

34. McKay LC, Adams L, Frackowiak RS, Corfield DR. A bilateral cortico-bulbar network associated with breath holding in humans, determined by functional magnetic resonance imaging. Neuroimage 2008; 40: 1824-1832, doi: 10.1016/j.neuroimage.2008.01.058.

35. Sugimori H, Ibayashi S, Fuji K, Sadoshima S, Kuwabara $Y$, Fujishima M. Can transcranial Doppler really detect reduced cerebral perfusion states? Stroke 1995; 26: 2053-2060, doi: 10.1161/01.STR.26.11.2053. 